\title{
BODY WEIGHT AND BLOOD PRESSURE
}

Mehmet Rami Helvaci (1)

Mustafa Yaprak (1)

Abdulrazak Abyad (2)

Lesley Pocock (3)

(1) Specialist of Internal Medicine, MD

(2) Middle-East Academy for Medicine of Aging, MD

(3) medi+WORLD International

\section{Correspondence:}

Dr Mehmet Rami Helvaci,

07400, ALANYA, Turkey

Phone: 00-90-506-4708759

Email: mramihelvaci@hotmail.com

Received: September 2020; Accepted: October 2020; Published: November1, 2020

Citation: Mehmet Rami Helvaci et al. Body weight and blood pressure. Middle East Journal of Nursing 2020; 14(2): 22-27

DOI: 10.5742/MEJN2020.93786

\section{Abstract}

Background: Body weight may have some effects on systolic and diastolic blood pressure (BP) in the body.

Methods: The study was performed in the Hematology and Internal Medicine Polyclinics on patients with sickle cell diseases (SCD) and routine check up cases.

Results: The study included 122 patients with the SCD (58 females) and 176 age and sex-matched control cases, totally. Mean age of patients with the SCD was 28.6 years. When we compared the patients and control groups, the mean body weight and body mass index were significantly retarded in patients with the SCD (71.6 versus $57.8 \mathrm{~kg}$ and 24.9 versus $20.7 \mathrm{~kg} / \mathrm{m} 2$, respectively, $p=0.000$ for both), whereas the mean body height was similar in both groups (166.1 versus $168.5 \mathrm{~cm}, p>0.05$ ). Parallel to the retarded mean body weight, mean values of the low density lipoproteins, high density lipoproteins, and alanine aminotransferase were also lower in patients with the SCD ( $p=0.000$ for all). Parallel to the retarded mean body weight again, mean values of the systolic and diastolic BP were significanly lower in patients with the SCD (113.3 versus 118.8 and 72.3 versus $83.6 \mathrm{mmHg}$, respectively, $\mathrm{p}<0.01$ for both).
Conclusion: Body weight may be the major determining factor of systolic and diastolic BP in the body.

Key words: Body weight, body mass index, blood pressure, metabolic syndrome 


\section{Introduction}

Chronic endothelial damage may be the most common type of vasculitis, and the leading cause of end-organ insufficiency, early aging, and premature death in human beings (1-4). Much higher blood pressure (BP) of the afferent vasculature may be the major underlying mechanism by inducing recurrent injuries on vascular endothelium. Probably, whole afferent vasculature including capillaries are mainly involved in the process. Therefore the term of venosclerosis is not as famous as atherosclerosis in the literature. Due to the chronic endothelial damage, inflammation, edema, and fibrosis, vascular walls thicken, their lumens narrow, and they lose their elastic nature, which eventually reduces blood flow to the terminal organs and increases systolic BP further. Some of the well-known underlying causes or indicators of the inflammatory process are physical inactivity, sedentary lifestyle, animal-rich diet, smoking, alcohol, overweight, hypertriglyceridemia, dyslipidemia, impaired fasting glucose, impaired glucose tolerance, white coat hypertension, chronic inflammation, prolonged infections, and cancers for the development of terminal consequences including obesity, hypertension $(\mathrm{HT})$, diabetes mellitus (DM), cirrhosis, peripheric artery disease (PAD), chronic obstructive pulmonary disease (COPD), coronary heart disease (CHD), chronic renal disease (CRD), mesenteric ischemia, osteoporosis, stroke, dementia, other endorgan insufficiencies, early aging, and premature death (5-7). Although early withdrawal of the underlying causes can delay terminal consequences, after development of HT, DM, cirrhosis, COPD, CRD, CHD, PAD, mesenteric ischemia, osteoporosis, stroke, dementia, other end-organ insufficiencies, and early aging, endothelial changes cannot be reversed completely due to their fibrotic natures The underlying causes and terminal consequences are researched under the titles of metabolic syndrome, aging syndrome, or accelerated endothelial damage syndrome in the literature, extensively (8-10). On the other hand, sickle cell diseases (SCD) are chronic inflammatory processes on vascular endothelium terminating with accelerated atherosclerosis induced end-organ failure and a shortened survival in both genders $(11,12)$. Hemoglobin $\mathrm{S}(\mathrm{Hb} \mathrm{S})$ causes loss of elastic and biconcave disc shaped structures of red blood cells (RBC). Probably loss of elasticity instead of shape is the main pathology since sickling is rare in peripheric blood samples of the patients with associated thalassemia minor, and human survival is not affected in hereditary spherocytosis or elliptocytosis. Loss of elasticity is present during the whole lifespan, but exaggerated with inflammations, infections, and various stresses of the body. The hard RBC induced chronic endothelial damage, inflammation, and fibrosis terminate with disseminated tissue hypoxia all over the body $(13,14)$. As a difference from other causes of chronic endothelial damage, the SCD may keep vascular endothelium particularly at the capillary level (15), since the capillary system is the main distributor of the hard RBC into the tissues. The hard cells induced chronic endothelial damage builds up an advanced atherosclerosis in younger ages of the patients. Vascular occlusions induced ischemia and infactions are the final consequences of the SCD, so the mean life expectancy is decreased by 25 to 30 years in the SCD (16).

\section{Material and Methods}

The study was performed in the Hematology and Internal Medicine Polyclinics of the Mustafa Kemal University on patients with the SCD and routine check up cases between March 2007 and April 2010. Only patients with the SCD on silent phase instead of the patients with painful crises were included into the study. SCD were diagnosed by the hemoglobin electrophoresis performed via high performance liquid chromatography. The control cases were age and sex-matched cases with the SCD. The medical history of all cases including already used medications was learnt, and a routine check up procedure including fasting plasma glucose (FPG), low density lipoproteins (LDL), high density lipoproteins (HDL), triglycerides (TG), and alanine aminotransferase (ALT) values were performed. Body weight and height were measured, and body mass index (BMI) of each case was calculated by the same physician instead of verbal expressions. Weight in kilograms is divided by height in meters squared (17). Systolic and diastolic BP were checked after a 5 minute rest in seated position by using the mercury sphygmomanometer (ERKA, Germany) with the same physician again, and no smoking was permitted during the previous 2 hours. Eventually, the mean body weight, height, BMI, FPG, LDL, HDL, TG, ALT, and systolic and diastolic BP were detected in each group, and compared in between. Mann-Whitney U Test, IndependentSamples t Test, and comparison of proportions were used as the methods of statistical analyses.

\section{Results}

The study included 122 patients with the SCD (58 females) and 176 age and sex-matched control cases (84 females), totally. The mean age of patients with the SCD was 28.6 years. When we compared the patients and control groups, the mean body weight and BMI were significantly retarded in patients with the SCD $(71.6$ versus $57.8 \mathrm{~kg}$ and 24.9 versus $20.7 \mathrm{~kg} / \mathrm{m} 2$, respectively, $p=0.000$ for both), whereas the mean body heights were similar in both groups (166.1 versus $168.5 \mathrm{~cm}, \mathrm{p}>0.05$ ). The mean values of the FPG were unchanged between the patients and control groups (93.9 versus $94.7 \mathrm{mg} / \mathrm{dL}$, respectively, $p>0.05)$, and the mean value of TG was higher in patients with the SCD, but the difference was non-significant (120.1 versus $112.1 \mathrm{mg} / \mathrm{dL}, \mathrm{p}>0.05)$. Parallel to the retarded mean body weight and $\mathrm{BMI}$, the mean values of LDL (74.0 versus $109.6 \mathrm{mg} / \mathrm{dL}$ ), HDL (24.4 versus 42.6 $\mathrm{mg} / \mathrm{dL}$ ), and ALT (34.9 versus $56.7 \mathrm{U} / \mathrm{L}$ ) were also lower in patients with the SCD, significantly $(p=0.000$ for all). Parallel to the retarded mean body weight again, mean values of the systolic and diastolic BP were significanly lower in patients with the SCD (113.3 versus 118.8 and 72.3 versus $83.6 \mathrm{mmHg}$, respectively, $p<0.01$ for both) (Table 1). On the other hand, six patients with the SCD (three females and three males with mean ages of 32.3 and 29.3 years, respectively) were lost due to intercurrent infections induced sepsis, and there were pulmonary HT 
Table 1: Characteristic features of the study cases

\begin{tabular}{|c|c|c|c|}
\hline Variables & Sickle cell cases & Control cases & $p$-value \\
\hline Number & 122 & 176 & \\
\hline Female ratio & $47.5 \%(58)$ & $47.7 \%(84)$ & Ns* \\
\hline Mean age (years) & $28.6 \pm 10.2(14-59)$ & $28.6 \pm 8.2(15-58)$ & Ns \\
\hline Mean weight (kq) & $\underline{57.8 \pm 11.0(31-83)}$ & $\underline{71.6 \pm 14.4(43-111)}$ & $\underline{0.000}$ \\
\hline Mean height $(\mathrm{cm})$ & $166.1 \pm 9.1(145-188)$ & $168.5 \pm 10.0(137-195)$ & Ns \\
\hline Mean BMIt $\left(\mathrm{ka} / \mathrm{m}^{2}\right)$ & $\underline{20.7 \pm 2.9(14.7-29.9)}$ & $\underline{24.9 \pm 4.3(17.3-41.2)}$ & $\underline{0.000}$ \\
\hline Mean $F P G=(\mathrm{mg} / \mathrm{dL})$ & $93.9 \pm 13.8(56-119)$ & $94.7 \pm 12.0(63-160)$ & Ns \\
\hline Mean $\operatorname{LDLS}(\mathrm{mq} / \mathrm{dL})$ & $74.0 \pm 29.8(24-164)$ & $\underline{109.6 \pm 29.6(43-231)}$ & $\underline{0.000}$ \\
\hline Mean $H D L \|(m a / d L)$ & $\underline{24.4 \pm 7.8(9-45)}$ & $\underline{42.6 \pm 11.0(24-91)}$ & $\underline{0.000}$ \\
\hline Mean trigycerides ( $\mathrm{mg} / \mathrm{dL}$ ) & $120.1 \pm 63.9(31-348)$ & $112.1 \pm 65.0(27-388)$ & Ns \\
\hline Mean ALTS $(U / L)$ & $\underline{34.9 \pm 20.5(11-125)}$ & $\underline{56.7 \pm 26.6(20-168)}$ & $\underline{0.000}$ \\
\hline Mean systolic $B P^{* *}(\mathrm{mmH})$ & $\underline{113.3 \pm 14.9(80-150)}$ & $\underline{118.8 \pm 16.6(80-170)}$ & $\underline{0.008}$ \\
\hline Mean diastolic BP $(\mathrm{mmHq})$ & $\underline{72.3 \pm 9.9(60-100)}$ & $83.6 \pm 10.7(60-110)$ & $\underline{0.000}$ \\
\hline
\end{tabular}

*Nonsignificant $(p>0.05) \quad †$ Body mass index $\quad$ FFasting plasma glucose $\S$ Low density lipoproteins $\|$ High density lipoproteins TAlanine aminotransferase ${ }^{* *}$ Blood pressure

in two, cirrhosis in two, and cirrhosis plus CRD in one of them. Additionally, all of the lost six patients were Hb SS in nature.

\section{Discussion}

HT may result from a complex interaction of genes and environmental factors. It is a sign that heart and blood vessels are being overworked. In most people with HT, increased total peripheral resistance accounts for HT while cardiac output remains normal (18). The increased peripheral resistance is mainly attributable to structural narrowing of small arteries and arterioles, although a reduction in the number of capillaries may also contribute (19). HT is rarely accompanied by symptoms in the shortterm. Symptoms attributed to HT may actually be related with associated anxiety rather than HT itself. However, $\mathrm{HT}$ may be a major risk factor for CHD, PAD, CRD, cirrhosis, COPD, stroke, and dementia-like end-organ insufficiencies in the long-term. For example, a reduction of the BP by $5 \mathrm{mmHg}$ can decrease the risk of stroke by $34 \%$ and $\mathrm{CHD}$ by $21 \%$, and reduce the likelihood of dementia, heart failure, and mortality from cardiovascular diseases (20). On the other hand, we cannot detect any underlying cause in about $95 \%$ of patients with HT. Physical inactivity, sedentary lifestyle, animal-rich diet, excess weight, smoking, alcohol, chronic inflammations, prolonged infections, and cancers may be some of the underlying risk factors of $\mathrm{HT}$.

Excess weight may be the major underlying cause of HT nowadays in the world. Adipose tissue produces leptin, tumor necrosis factor-alpha, plasminogen activator inhibitor-1, and adiponectin-like cytokines, acting as acute phase reactants in the plasma (21). Excess weight-induced chronic low-grade vascular endothelial inflammation plays a significant role in the pathogenesis of accelerated atherosclerosis in the whole body (22). Additionally, excess weight leads to myocardial hypertrophy terminating with a decreased cardiac compliance. A combination of these cardiovascular risk factors eventually terminates with increased risks of arrhythmias, cardiac failure, and sudden cardiac death. Similarly, the prevalence of CHD 
and stroke increased parallel to the increased BMI in the other studies $(23,24)$, and risk of death from all causes including cancers increased throughout the range of moderate to severe weight excess in all age groups (25). The relationship between excess weight, elevated BP, and hypertriglyceridemia is described in the metabolic syndrome, and clinical manifestations of the syndrome include obesity, dyslipidemia, $\mathrm{HT}$, insulin resistance, and proinflammatory and prothrombotic states (9). Similarly, prevalence of excess weight, DM, HT, and smoking were all higher in the hypertriglyceridemia group $(200 \mathrm{mg} / \mathrm{dL}$ and higher) in another study (26).

SCD include a group of genetic disorders characterized by the presence of $\mathrm{Hb} \mathrm{S}$, which is the first discovered hemoglobinopathy, and it has been known for 100 years (27). Together with the hemoglobin E, it is the most commonly seen hemoglobinopathy in the world. $\mathrm{Hb} \mathrm{S}$ causes erythrocytes to change their normal biconcave disc shape to a crescent or sickle shape during various stresses of the body. The erythrocytes can take their normal shapes after normalization of the stressful conditions, but after repeated cycles of sickling and unsickling, they are damaged permanently, and hemolysis occurs. So lifespan of the erythrocytes decreases from the normal 120 days to $15-25$ days. This hemolysis is responsible for the anemia that is the hallmark of the SCD. Painful crises are the most disabling symptoms of the SCD. Although painful crises may not be life threatening directly (28), infections are the most common triggering factors of the crises. So the risk of mortality is significantly higher during the crises. On the other hand, pain is the result of a complex and poorly understood interaction between erythrocytes, endothelium, leukocytes, and platelets. Probably, leukocytosis contributes to the pathogenesis of the painful crises by releasing several cytotoxic enzymes. The adverse actions of neutrophils on endothelium are of particular interest with regard to stroke and cerebrovascular diseases in the SCD. For example, leukocytosis in the absence of any infection was an independent predictor of the severity of the SCD in a previous study (29), and it was associated with an increased risk of stroke in a cohort of Jamaican patients (30). Occlusions in vasculature of the bone marrow, bone infarctions, inflammatory mediators, and activation of afferent nerves may take a role in the pathophysiology of the severe pain. Due to the severity of pain, narcotic analgesics are usually required (31). According to our experience, the painful crises are the most significant problems for the patients, for their families, for health professionals, and even for other patients due to the severity and prolonged nature of the episodes.

Due to the repeated infarctions and subsequent fibrosis, the spleen is commonly very small in adults. Eventually, a functional and anatomic asplenism develops due to the decreased antibody production, opsonization, and reticuloendothelial functions. Terminal consequence of the asplenism is increased risk of infections with Streptococcus pneumoniae, Haemophilus influenzae, and Neisseria meningitidis-like encapsulated bacteria. Therefore, especially pneumococcal infections are common in early childhood, and are associated with a high mortality rate. The causes of death were infection in $56 \%$ of infants in a previous study (29). In another study, the peak incidence of death among children with the SCD occured between 1 and 3 years of age, and the deaths among patients less than 20 years of age were predominantly caused by pneumococcal sepsis (32). Adults, even those who appear relatively fit, are susceptible to acute multiorgan failures, sepsis, and sudden death during acute painful crises due to the severe immunosuppression.

SCD can affect nearly all organ systems of the body (33-35). Aplastic crises, sequestration crises, hemolytic crises, acute chest syndrome, avascular necrosis of the femoral and humeral heads, priapism and infarction of the penis, osteomyelitis, acute papillary necrosis of kidneys, chronic renal failure, occlusion of retinal arteries and blindness, pulmonary HT, bone marrow necrosis induced dactilitis in children, chronic punched-out ulcers around ankles, hemiplegia, and cranial nerve palsies are only some of the presentation types of the SCD. Eventually, the median ages of death were 42 years in males and 48 years in females in the literature (16), whereas they were 29.3 and 32.3 years, respectively, in the present study. The great differences may be secondary to delayed diagnosis, delayed initiation of hydroxyurea therapy, and inadequate RBC supports during emergencies in Antakya region of Turkey (36). Actually, RBC supports must be given immediately during all medical or surgical events in which there is an evidence of clinical deterioration in the SCD (37). RBC supports decrease sickle cell concentration in circulation, and suppress bone marrow about the production of abnormal RBC. So it decreases sickling-induced endothelial damage and inflammation all over the body. As a result of such a great variety of clinical presentation types, it is not surprising to see that the mean body weight and BMI were significantly retarded in patients with the SCD in the present study. On the other hand, as an opposite finding to some other reports (38$39)$, the mean body heights were similar in patients with the SCD and control cases in the present study. Probably due to the significantly lower mean body weight and BMI, mean values of the LDL, ALT, and systolic and diastolic BP were also lower in the SCD, which can be explained by definition of the metabolic syndrome again (40-42).

As a conclusion, body weight may be the major determining factor of systolic and diastolic BP in the body. 


\section{References}

1. Widlansky ME, Gokce N, Keaney JF Jr, Vita JA. The clinical implications of endothelial dysfunction. J Am Coll Cardiol 2003; 42(7): 1149-1160.

2. Ridker PM. High-sensitivity C-reactive protein: potential adjunct for global risk assessment in the primary prevention of cardiovascular disease. Circulation 2001; 103(13): 1813-1818.

3. Helvaci MR, Seyhanli M. What a high prevalence of white coat hypertension in society! Intern Med 2006; 45(10): 671-674

4. Helvaci MR, Kaya H, Seyhanli M, Cosar E. White coat hypertension is associated with a greater all-cause mortality. J Health Sci 2007; 53(2): 156-160.

5. Helvaci MR, Kaya H, Seyhanli M, Yalcin A. White coat hypertension in definition of metabolic syndrome. Int Heart J 2008; 49(4): 449-457.

6. Helvaci MR, Sevinc A, Camci C, Yalcin A. Treatment of white coat hypertension with metformin. Int Heart J 2008; 49(6): 671-679.

7. Helvaci MR, Aydin Y, Gundogdu M. Smoking induced atherosclerosis in cancers. HealthMED 2012; 6(11): 3744 3749 .

8. Eckel RH, Grundy SM, Zimmet PZ. The metabolic syndrome. Lancet 2005; 365(9468): 1415-1428.

9. Tonkin AM. The metabolic syndrome(s)? Curr Atheroscler Rep 2004; 6(3): 165-166.

10. Franklin SS, Barboza MG, Pio JR, Wong ND. Blood pressure categories, hypertensive subtypes, and the metabolic syndrome. J Hypertens 2006; 24(10): 20092016.

11. Helvaci MR, Yaprak M, Abyad A, Pocock L. Atherosclerotic background of hepatosteatosis in sickle cell diseases. World Family Med 2018; 16(3): 12-18.

12. Helvaci MR, Davarci M, Inci M, Yaprak M, Abyad A, Pocock L. Chronic endothelial inflammation and priapism in sickle cell diseases. World Family Med 2018; 16(4): 6 11.

13. Helvaci MR, Gokce C, Davran R, Akkucuk S, Ugur M, Oruc C. Mortal quintet of sickle cell diseases. Int J Clin Exp Med 2015; 8(7): 11442-11448.

14. Helvaci MR, Kaya H. Effect of sickle cell diseases on height and weight. Pak J Med Sci 2011; 27(2): 361-364.

15. Yawn BP, Buchanan GR, Afenyi-Annan AN, Ballas SK, Hassell KL, James $\mathrm{AH}$, et al. Management of sickle cell disease: summary of the 2014 evidence-based report by expert panel members. JAMA 2014; 312(10): 1033-1048.

16.Platt OS, Brambilla DJ, Rosse WF, Milner PF, Castro $\mathrm{O}$, Steinberg $\mathrm{MH}$, et al. Mortality in sickle cell disease. Life expectancy and risk factors for early death. N Engl J Med 1994; 330(23): 1639-1644.

17. Third Report of the National Cholesterol Education Program (NCEP) Expert Panel on Detection, Evaluation, and Treatment of High Blood Cholesterol in Adults (Adult Treatment Panel III) final report. Circulation 2002; 106(25): 3143-3421.
18. Conway J. Hemodynamic aspects of essential hypertension in humans. Physiol Rev 1984; 64(2): 617660.

19. Folkow B. Physiological aspects of primary hypertension. Physiol Rev 1982; 62(2): 347-504.

20. Law M, Wald N, Morris J. Lowering blood pressure to prevent myocardial infarction and stroke: a new preventive strategy. Health Technol Assess 2003; 7(31): 1-94.

21. Funahashi T, Nakamura T, Shimomura I, Maeda K, Kuriyama $\mathrm{H}$, Takahashi $\mathrm{M}$, et al. Role of adipocytokines on the pathogenesis of atherosclerosis in visceral obesity. Intern Med 1999; 38(2): 202-206.

22. Yudkin JS, Stehouwer CD, Emeis JJ, Coppack SW. C-reactive protein in healthy subjects: associations with obesity, insulin resistance, and endothelial dysfunction: a potential role for cytokines originating from adipose tissue? Arterioscler Thromb Vasc Biol 1999; 19(4): 972-978.

23. Zhou B, Wu Y, Yang J, Li Y, Zhang H, Zhao L. Overweight is an independent risk factor for cardiovascular disease in Chinese populations. Obes Rev 2002; 3(3): 147-156.

24. Zhou BF. Effect of body mass index on all-cause mortality and incidence of cardiovascular diseases--report for meta-analysis of prospective studies open optimal cutoff points of body mass index in Chinese adults. Biomed Environ Sci 2002; 15(3): 245-252.

25. Calle EE, Thun MJ, Petrelli JM, Rodriguez C, Heath CW Jr. Body-mass index and mortality in a prospective cohort of U.S. adults. N Engl J Med 1999; 341(15): 10971105.

26. Helvaci MR, Aydin LY, Maden E, Aydin Y. What is the relationship between hypertriglyceridemia and smoking? Middle East J Age and Ageing 2011; 8(6).

27. Herrick JB. Peculiar elongated and sickle-shape red blood corpuscles in a case of severe anemia. Arch Intern Med (Chic) 1910; VI(5): 517-521.

28. Parfrey NA, Moore W, Hutchins GM. Is pain crisis a cause of death in sickle cell disease? Am J Clin Pathol 1985; 84(2): 209-212.

29. Miller ST, Sleeper LA, Pegelow CH, Enos LE, Wang WC, Weiner SJ, et al. Prediction of adverse outcomes in children with sickle cell disease. N Engl J Med 2000; 342(2): 83-89.

30. Balkaran B, Char G, Morris JS, Thomas PW, Serjeant BE, Serjeant GR. Stroke in a cohort of patients with homozygous sickle cell disease. J Pediatr 1992; 120(3): 360-366.

31. Cole TB, Sprinkle RH, Smith SJ, Buchanan GR. Intravenous narcotic therapy for children with severe sickle cell pain crisis. Am J Dis Child 1986; 140(12): 12551259.

32. Leikin SL, Gallagher D, Kinney TR, Sloane D, Klug P, Rida W. Mortality in children and adolescents with sickle cell disease. Cooperative Study of Sickle Cell Disease. Pediatrics 1989; 84(3): 500-508.

33. Haupt HM, Moore GW, Bauer TW, Hutchins GM. The lung in sickle cell disease. Chest 1982; 81(3): 332-337. 
34. Shapiro MP, Hayes JA. Fat embolism in sickle cell disease. Report of a case with brief review of the literature. Arch Intern Med 1984; 144(1): 181-182.

35. Hutchinson RM, Merrick MV, White JM. Fat embolism in sickle cell disease. J Clin Pathol 1973; 26(8): 620-622.

36. Helvaci MR, Aydin Y, Ayyildiz O. Hydroxyurea may prolong survival of sickle cell patients by decreasing frequency of painful crises. HealthMED 2013; 7(8): 23272332.

37. Davies SC, Luce PJ, Win AA, Riordan JF, Brozovic $M$. Acute chest syndrome in sickle-cell disease. Lancet 1984; 1(8367): 36-38.

38. Al-Saqladi AW, Cipolotti R, Fijnvandraat K, Brabin BJ. Growth and nutritional status of children with homozygous sickle cell disease. Ann Trop Paediatr 2008; 28(3): 165189.

39. Zemel BS, Kawchak DA, Ohene-Frempong K, Schall $\mathrm{JI}$, Stallings VA. Effects of delayed pubertal development, nutritional status, and disease severity on longitudinal patterns of growth failure in children with sickle cell disease. Pediatr Res 2007; 61(5 Pt 1): 607-613.

40. Helvaci MR, Kaya H, Yalcin A, Kuvandik G. Prevalence of white coat hypertension in underweight and overweight subjects. Int Heart J 2007; 48(5): 605-613.

41. Helvaci MR, Kaya H, Duru M, Yalcin A. What is the relationship between white coat hypertension and dyslipidemia? Int Heart J 2008; 49(1): 87-93.

42. Helvaci MR, Kaya H, Sevinc A, Camci C. Body weight and white coat hypertension. Pak J Med Sci 2009; 25(6): 916-921. 